\title{
Mídia, formação da opinião pública e voto popular: As narrativas de crime na TV e o referendo sobre o comércio de armas'
}

\author{
Paulo Vaz ${ }^{2}$ \\ Mauricio Lissovsky \\ Guilherme Pecly \\ Maria Fantinato \\ Mariana Pombo \\ UFRJ
}

\begin{abstract}
Resumo: $O$ artigo avança uma hipótese para explicar a súbita e intensa mudança de opinião sobre o comércio de armas após o início do horário eleitoral gratuito em outubro de 2005. A mudança teria acontecido porque a propaganda favorável à manutenção do comércio de armas soube explorar a percepção de segurança pública construída ao longo dos anos pelas narrativas midiáticas de crimes. Para dar sustentação empírica à hipótese, analisamos a cobertura de crime do RJ-TV, segunda edição, durante o ano de 2004.
\end{abstract}

Palavras-chave: mídia, opinião, referendo, crime, vítima virtual.

Abstract: This article develops a hypothesis to explain the sudden, intense shift in voters' opinions on gun control following television campaign advertisements in October 2005. We argue that the shift occurred because the ads supporting the maintenance of the gun trade were successful in exploiting popular perceptions of public security constructed over the years by mediatic crime narratives. We base our hypothesis on an empirical analysis of the crime coverage in the nightly edition of RJ-TV, the most watched local news show in Rio de Janeiro, in the year 2004.

Key words: media, opinion, referendum, crime, virtual victim.

\footnotetext{
${ }^{1}$ Este artigo analisa como as narrativas de crime na TV construíram um ambiente semântico constrangendo os argumentos possíveis de serem usados no horário gratuito sobre o referendo; num próximo artigo, analisaremos com detalhe o uso pelas campanhas do SIM e do NÃO da percepção de segurança pública construída pela mídia.

2 Paulo Vaz é professor do programa de pós-graduação da ECO-UFRJ e pesquisador do CNPq e da FAPERJ; Maurício Lissovsky também é professor do programa de pós-graduação da ECO; Guilherme Pecly, Maria Fantinato e Mariana Pombo são bolsistas de Iniciação Científica do CNPq e alunos de graduação na mesma instituição.
} 
Résumé: L'article avance une hypothèse pour expliquer le brusque changement d'opinion sur le commerce d'armes après le début de l'horaire électoral gratuit en octobre 2005. Le changement serait arrivé parce que la propagande favorable à la maintenance du commerce d'armes a su explorer la perception de sécurité publique construit au cours des ans par les narratives médiatiques de crimes. Pour donner soutenance empirique à cette hypothèse, nous avons analysé la couverture de crime faite par le RJ-TV, seconde édition, pendant 2004.

Mots-clés: média, opinion, référendum, crime, victime virtuelle.

\section{1 - Introdução}

O referendo sobre a proibição do comércio de armas no Brasil é um acontecimento privilegiado para se analisar a relação entre meios de comunicação e formação de opinião no Brasil. A razão é a rápida e intensa mudança de atitude após o começo da propaganda gratuita no rádio e na TV.

De início, todos os institutos de pesquisa de opinião apresentavam uma situação que parecia claramente favorável à proibição: em abril de 2005, por exemplo, o Datafolha divulgou uma pesquisa mostrando que, na cidade de São Paulo, 83\% do público era contra a venda de armas; até às vésperas da campanha, outros institutos continuavam a assinalar amplas maiorias (entre 70 e $80 \%$ ) a favor da proibição. Contudo, no dia 3 de outubro, dois dias após o início do período de propaganda gratuita, o tracking da campanha do SIM (o voto favorável à proibição do comércio) já assinalava uma queda abrupta: os eleitores contrários ao comércio representavam agora apenas $55 \%$ do total. No dia 15 , com cerca de duas semanas após o início da veiculação das mensagens, uma pesquisa nacional do Ibope registrou a virada: o SIM caiu para $45 \%$ e o NÃO respondia por $49 \%$ das intenções de voto3. A diferença continuou a crescer até a votação; o resultado final no estado de São Paulo foi de $40 \%$ para o SIM e de 60\% para o NÃO; no estado do Rio de Janeiro, foi de $38 \%$ a $62 \%$, respectivamente.

\footnotetext{
3 Para uma análise mais detalhada dos dados do tracking da campanha do SIM e da sua relação com as estratégias de mídia de ambas as campanhas ver Lissovsky, 2006.
} 
A rapidez e a extensão da mudança de atitudes sugerem que a propaganda gratuita teve influência direta sobre o voto dos indivíduos. A análise dos grupos focais realizados no âmbito da Campanha do SIM, empreendida por Vital da Cunha, corrobora, em larga medida, essa hipótese. Vital da Cunha mostrou, em primeiro lugar, que os participantes tinham ouvido falar do desarmamento, mas pouco sabiam do referendo antes do início da campanha e que, em segundo lugar, a partir do quarto dia do horário gratuito, eles começaram a discutir com vigor os argumentos propostos pelas propagandas e se recordavam de alguns spots marcantes (Cunha, 2006). As peças publicitárias e os programas gratuitos forneceram, portanto, argumentos a partir dos quais os indivíduos confrontaram e justificaram suas interpretações e decisões.

Se é possível atribuir à campanha na tevê o papel de "causa" das atitudes ou decisões dos eleitores, os efeitos desta causa não são necessariamente evidentes. Isto é, os modos pelos quais essa causa opera precisam ainda ser determinados, pois dependem amplamente das características do "objeto" sobre o qual ela se exerce. De fato, o principal objetivo deste artigo é examinar alguns desses modos de operação da “causa" propaganda, em particular aqueles vinculados à difusão de percepções sobre violência, crime e segurança pública nos noticiários da televisão brasileira.

Para tornar esta análise mais acurada, é necessário distinguir o "Referendo das Armas" de uma campanha eleitoral típica. Em um processo eleitoral comum, as mensagens veiculadas pelas propagandas dos candidatos são constrangidas por relações prévias de pertencimento de uma candidatura (isto é, em larga medida os candidatos são percebidos como pertencendo a um dado grupo político, e eventualmente vinculados a este ou aquele governo). A esta forma de agrupamento dos candidatos vem sobrepor-se no Brasil, como muitos autores já o assinalaram, uma distinção fundamental "nós-eles" que constitui, de um lado, os eleitores (usualmente representado como o "povo", ou "os trabalhadores") e, de outro, os políticos e o governo.

Embora o formato do referendo - tanto no que diz respeito às regras da propaganda gratuita, quanto à institucionalização das posições através de "frentes parlamentares” e à dinâmica eleitoral propriamente dita - fosse em larga medida 
semelhante ao das eleições tradicionais, o referendo ocorreu em um ano sem eleições e os políticos pouco foram chamados a se posicionar (ou sentiram-se obrigados a isso). Ao mesmo tempo, não ficou claro, antes e ao longo do período de propaganda gratuita, que o referendo tinha se originado em campanhas da sociedade civil, que decorria de consulta do Poder Legislativo à população e que a proibição do comércio foi apoiada pela grande maioria dos partidos políticos. Desse modo, as mensagens veiculadas pelas campanhas do SIM e do NÃO, ainda que percebidas como de natureza política, começaram a ser difundidas sem que os campos de pertencimento e de distinção "nós-eles" estivessem bem definidos. É bastante provável, nessas circunstâncias, que o potencial de persuasão das mensagens seja consideravelmente amplificado. Uma vez que os campos a partir dos quais as mensagens persuasivas seriam veiculadas estavam relativamente indeterminados, as campanhas poderiam, com mais liberdade do que nas campanhas eleitorais típicas, escolher a partir de que parcela da realidade social e de quais processos identitários estabelecer motivações e difundir cenários que dessem sentido a uma decisão acerca do comércio de armas.

É preciso ressaltar que a sugestão de prognósticos e a constituição de uma distinção "nós-eles" não ocorreram no vácuo. As notícias sobre "violência" urbana nos meios de comunicação eram seguramente um campo a ser explorado para a construção de cenários e de processos de identificação dos eleitores. Assim, definir os modos como a mídia formou a opinião dos eleitores, isto é, os modos pelos quais a "causa" produziu seus "efeitos", envolve claramente dois aspectos: as campanhas a favor e contra a proibição, "agindo" direta e imediatamente sobre os eleitores; e o "efeito" cumulativo e de longo prazo, que corresponde à constituição cotidiana de uma percepção sobre a realidade do crime.

A análise do referendo nos interessa não apenas por ajudar a compreender como os meios de comunicação são capazes de "formar opinião", mas, igualmente, por revelar os limites deste seu poder. No que diz respeito ao referendo, é notável que, com a esperada exceção da revista Veja, devidamente explorada pela campanha do NÃO, os jornais tidos como formadores de opinião (O Globo e Folha de S. Paulo) 
se posicionaram a favor da proibição do comércio de armas ${ }^{4}$ O grande número de artistas que apareceram nos spots e no programa do SIM nos primeiros dez dias da campanha criou inclusive a percepção de que a mídia e, em particular a Rede Globo, apoiava a proibição do comércio de armas (e, na visão de alguns eleitores, o próprio referendo atendia a interesses desta emissora). A derrota do SIM sinalizou para muitos analistas que a mídia tinha perdido o poder de formar a opinião. Mas o que a campanha do referendo tornou de fato evidente foi a diferença entre produzir editoriais ou estimular artistas a defender o desarmamento e a embocadura cotidiana que "expõe a realidade" do crime na forma da denúncia. Às manifestações editoriais ou ao depoimento de artistas, a audiência sempre foi capaz de atribuir "outros interesses"; já no dispositivo noticioso, o visto e o escrito contribuem decisivamente para dar forma e sentido ao que se pensa ser a realidade. Embora veículos como O Globo e a Revista Época tenham se esforçado em difundir informações que corroboravam argumentos defendidos pelo SIM, elas foram claramente insuficientes para convencer a maior parte da audiência que a realidade do crime, elaborada por estes mesmo veículos, era apenas uma, entre muitas, construções possíveis.

Na seqüência deste artigo, discutiremos teoricamente como as notícias de crime na sociedade contemporânea promovem a vitimização vicária - de fato, produzem a subjetividade da vítima virtual ao promoverem o medo do crime - e constroem a responsabilidade do Estado. Apresentaremos depois os resultados de uma pesquisa empírica sobre a cobertura de crimes ocorridos na cidade do Rio de Janeiro feita pelo RJ-TV $2^{\text {a }}$ edição no ano de 2004. No final, argumentaremos que as narrativas de crime constituíram linhas de força limitando os argumentos que fariam sentido para a decisão sobre o comércio de armas.

\section{2 - A vítima virtual e o sofrimento evitável}

Em sua forma abstrata, o nexo entre mídia e medo do crime pode ser exposto como uma questão: que mecanismos editoriais e retóricos favorecem a identificação entre espectador e vítima? Mais precisamente, quais são as condições

\footnotetext{
4 A legislação eleitoral restringe a manifestação explícita de posições na televisão e no rádio. Mesmo assim, o jornalismo da TV Bandeirante deu seguidas mostras de sua preferência pelo NÃO. A TV Globo, ainda que notoriamente favorável ao SIM, agiu com relativa "neutralidade", ao menos durante o período oficial da campanha.
} 
para que uma notícia sobre o sofrimento de estranhos seja a ocasião de tornar este sofrimento uma possibilidade no futuro imaginado por cada leitor ou espectador, orientando suas ações cotidianas e suas vinculações sociopolíticas?

Conceituar esses mecanismos implica analisar os procedimentos que, partindo de uma notícia sobre um crime, ampliam o número de vítimas possíveis e propõem sua repetição provável no futuro. Em outras palavras, o consumo de notícias sobre crime deve favorecer duas transformações na mente da audiência: 1) pensar que o sofrimento ocorrido poderia ter acontecido com qualquer um; 2) pensar que o sofrimento ocorrido pode ocorrer novamente.

Um primeiro fator para produzir a generalização da possibilidade de ser vítima é o tipo de relação entre agressor e vítima que é privilegiado pelos jornais. Um homicídio cometido por amigos, familiares ou por razões passionais tende a permanecer localizado aos envolvidos. Embora a audiência possa se compadecer do sofrimento narrado, é plausível supor que a maioria julgue estar à distância de tal tipo de incidente, ou pense que suas pendências amorosas ou familiares encontram outra forma de resolução. Inversamente, um crime cometido por um estranho que selecionou aleatoriamente sua vítima, a qual nada fez para se colocar em perigo, tende a generalizar ao máximo as vítimas possíveis. Pensemos num assalto a um transeunte. Imaginemos que a rua seja movimentada, que ainda era dia e que a vítima estava em alguma atividade rotineira. O criminoso vitimou aquele inocente específico, mas poderia ter escolhido qualquer outro que estivesse no mesmo momento e lugar. A tendência de quem consome tal notícia é pensar que também poderia ter sido a vítima e que foi só por alguma decisão banal que não se tornou o alvo do criminoso. Desse modo, os crimes que favorecem a vitimização vicária são os que ocorrem ou no espaço público ou em lugares onde deveríamos estar protegidos e que implicam seleção aleatória de vítimas - em outras palavras, a audiência tende a pensar que o sofredor não se colocou voluntariamente numa situação de risco.

Pode parecer que a generalização da possibilidade de se tornar vítima já garante sua repetição no futuro. Mas analiticamente os dois aspectos devem ser separados, pois a generalização é condição necessária, mas não suficiente, para a entrada do acontecimento no horizonte de expectativas dos indivíduos. O atentado 
terrorista de 11 de Setembro é um exemplo particularmente claro da distância entre um indivíduo pensar que o que aconteceu poderia ter acontecido com vários, inclusive com ele, e pensar que o que aconteceu pode acontecer novamente, dessa vez lhe atingindo. $\mathrm{O}$ fato de $\mathrm{o}$ atentado ter ocorrido não implicava que novos atentados se sucederiam. Para manter a população dos Estados Unidos na preocupação com um novo ataque, foram necessárias a construção da Al-Qaeda como uma organização descentralizada, de células autônomas espalhadas pelo mundo com membros dispostos a tudo, e a mudança quase semanal no sistema de alerta que 'informava' a população sobre o risco de um novo ataque.

Para a cidade do Rio de Janeiro, um modo de construir a possibilidade de repetição futura é a própria cotidianidade de notícias sobre crimes similares. Um caso é dado pelos tiroteios entre traficantes ou entre traficantes e policiais que paralisam algumas das vias expressas da cidade. A cada novo incidente, a audiência, já habituada com esse tipo de notícia, será capaz de recordar casos semelhantes, mesmo sem a ajuda do jornal. Os que têm apenas a experiência mediada da cidade, como turistas ou idosos, tendem a crer que, a todo momento, o visto ou lido pode se concretizar; para os que também experimentam o cotidiano da cidade, onde na maior parte das vezes nada acontece, a possibilidade de tiroteios numa via expressa tornase como que um pano de fundo orientando a busca de sinais de irregularidade - "há policiais com armas à vista parados no meio da pista perto de uma favela; será uma 'falsa blitz'? Ou uma mera operação policial? De todo modo, é melhor torcer para que a polícia não pare o carro, pois algum tiroteio pode acontecer" - e aconselhando a prudência em passar pela via expressa em certas horas do dia.

Não precisa ser o mesmo incidente, só mudando os atores ou o dia; basta haver semelhança dos locais de ocorrência e de relação entre vítima e agressor para se favorecer a possibilidade de repetição na mente da audiência: entre uma vitimização por tiroteio de um transeunte, um assalto a carro e um assalto a passageiros num ônibus, a semelhança das situações é imediata e os leitores ou espectadores tendem a construir as ruas da cidade como lugares perigosos.

No mais das vezes, os meios de comunicação facilitam o trabalho da audiência: associam o acontecimento a casos semelhantes ocorridos anteriormente 
ou fornecem algum dado estatístico, apresentando assim o incidente como uma incidência, como mais um caso de um fenômeno geral que antecedeu e sucederá a qualquer uma de suas manifestações. Às vezes, a mídia sequer recorda casos semelhantes ou apresenta dados, mas pura e simplesmente vincula o incidente singular a uma situação genérica da cidade, como na frase de uso corrente pelos jornais para introduzir a notícia sobre um crime qualquer: "mais uma vítima da violência na cidade'.

Uma segunda estratégia retórica é a construção da imagem do agressor. Cada vez menos aqueles que cometem crimes são descritos como indivíduos cujas ações são condicionadas pelo contexto social ou causadas por paixões; ao contrário, quase sempre são referidos como agentes genéricos - bandidos, criminosos, traficantes - e seus atos, ao invés de terem justificativas, são marcados por um desrespeito pela vida humana que os torna ainda mais incompreensíveis e condenáveis. Esses agentes genéricos são também descritos como muito poderosos; diversas notícias de crime na cidade do Rio de Janeiro contêm menções aos tipos de armamentos dos traficantes, normalmente com siglas misteriosas que só nos fazem sonhar com o poder de destruição que está nos ameaçando.

Os meios de comunicação no Rio de Janeiro constroem uma imagem muito assustadora da cidade. Sabemos diariamente de crimes 'violentos' ocorridos em locais onde os cidadãos deveriam estar protegidos. Grande parte desses crimes foi cometida por estranhos fortemente armados e sem nenhum respeito pela vida humana. Em outras palavras, sabemos que novos crimes ocorrerão, mas estamos totalmente incertos a respeito de seu quando, onde e a quem eles atingirão. De um lado, a certeza da repetição; de outro, a incerteza sobre a eficácia de qualquer ação preventiva individual para evitar a vitimização. Incerteza, porém, que não conduz ao fatalismo, pois a exposição midiática do sofrimento de estranhos é habitualmente acompanhada da atribuição de responsabilidade. Além de pensar que poderia ter acontecido com qualquer um e que pode acontecer novamente, o consumo de notícias de crime incita a audiência a pensar que o sofrimento que ocorreu poderia não ter acontecido. Entramos na esfera do conceito de risco, com seu modo singular de construir a idéia de sofrimento evitável. 
Numa definição simples, o conceito de risco implica a construção de uma dupla contingência do futuro antecipado no presente: o sofrimento a vir é meramente provável e, sobretudo, depende de uma decisão de um dado agente (Luhmann, 1993). Esse modo de articular sofrimento e ação humana não funciona apenas no eixo conectando a decisão presente a conseqüências negativas; ele vigora também na busca de um vínculo entre um sofrimento presente e uma decisão passada. O conceito de risco torna-se então o vocabulário de atribuição de responsabilidade próprio da cultura contemporânea, deslocando as explicações estruturais para os sofrimentos humanos próprias da cultura moderna, com seu sonho utópico de engenharia social, de transformação da sociedade como modo de reduzir os sofrimentos humanos.

Concretamente, numa notícia de crime, a construção da idéia de sofrimento evitável não aponta mais para a desigualdade social ou para o vínculo dos aparatos de Estado com estruturas sociais injustas, o que implicava, em última instância, a colocar a audiência como co-responsável dos sofrimentos narrados, na medida em que ela podia e devia mobilizar-se para transformar a sociedade. Ela aponta, sim, para uma falha, uma incompetência, dos aparatos estatais de prevenção, julgamento e punição (Simon, 2007). De imediato, a audiência - ou melhor, o agregado dos em perigo - é situada como um cliente dos serviços de segurança do Estado; em termos de vinculação ideológica, o máximo a que se chega é denunciar uma excessiva brandura do Estado em relação aos criminosos, leniência que significaria desrespeito pelas vítimas reais e virtuais.

Nas sociedades ocidentais contemporâneas, estamos experimentando uma nova forma de relação entre indivíduo e Estado que pode ser conceituada como a emergência do direito ao risco. De um lado, isso significa que o indivíduo quer autonomia nas decisões sobre o quão arriscado ele quer ser em relação a um determinado prazer. A contrapartida é a transferência de responsabilidade do Estado para o indivíduo nos cuidados com saúde, emprego e educação, já bem descrita por aqueles que analisaram o Estado neoliberal. Se bem cuidarem de suas vidas, os indivíduos podem evitar uma série de sofrimentos futuros. De outro lado, os indivíduos também querem ser autônomos em relação às decisões sobre os riscos que 
desejam correr. Desse modo, irão requerer a proteção do Estado em relação àqueles que os expuseram a riscos que não desejaram correr: basta lembrar dos temas do fumante passivo ou das substâncias cancerígenas nos alimentos para percebermos a disseminação desse outro aspecto do direito ao risco. Mas é exatamente a partir dessa demanda de intervenção que reaparece o Estado autoritário.

No caso do crime no Rio de Janeiro, é comum que a notícia de uma experiência de sofrimento venha acompanhada de denúncias sobre a polícia não estar onde deveria ou sobre a ineficácia de sua proximidade - 'o assalto ocorreu a 100 metros da cabine de polícia'. Há também comentários sobre a legislação branda que permite a impunidade de criminosos e ironias acerca da incapacidade das prisões em evitar fugas ou impedir que os criminosos se organizem e continuem a cometer crimes: elas seriam queijos suíços, hotéis de cinco estrelas ou escritórios do crime organizado. Se conjugarmos esses comentários à desumanidade dos criminosos, percebe-se qual é a possibilidade política de se evitar sofrimentos futuros: mais policiamento nas ruas, de preferência pelo exército, que não estaria corrompido; leis mais duras e prisões que efetivamente isolem os criminosos da sociedade.

É preciso dizer que a vítima virtual é, muito concretamente, uma vítima. Assim como devemos evitar certos alimentos prazerosos para nos prevenir de doenças futuras, restringimos nossas oportunidades de prazer tendo em vista a eventualidade de vitimização. Sofremos agora para evitar sofrimentos futuros; contudo, esse sofrimento voluntário no presente não tem o contorno psicológico e a satisfação da ascese. A escolha pela limitação das oportunidades de prazer foi imposta pela presença de criminosos e pela incompetência do Estado. Na utopia da vítima virtual, a vitimização por um outro desumano não deveria ser conseqüência provável da busca prudente do prazer.

As notícias de crime promovem a subjetividade da vítima virtual, que se caracteriza tanto pelo temor de se tornar uma vítima a partir das notícias de crime que consome, quanto por se conceber como um cliente que faz sua parte - paga os impostos - mas que não recebe os serviços de segurança a que teria direito (Comaroff \& Comaroff, 2006; Garland, 2001). Estruturam, por isso mesmo, uma separação entre "nós' e “eles"; de um lado, imediatamente, estão os "cidadãos de bem", 
caracterizados pela tolerância, pelo respeito à vida humana, por cumprirem sua obrigação de contribuintes e pela possibilidade de se tornarem vítimas; de outro lado, estão os bandidos sem respeito algum pela vida alheia. Oscilando entre o "nós" e o “eles” estão os representantes dos aparatos estatais de prevenção, julgamento e punição; dependendo da notícia, podem estar seja ao lado do cidadão de bem, protegendo-o, seja ao lado dos bandidos, na medida em que, por corrupção ou incompetência, não conseguem conter o risco que trazem.

\section{3 - O crime na TV}

A pesquisa empírica sobre as características da cobertura de crime do RJ-TV segunda edição (noturno, por volta de $19 \mathrm{~h}$ ) adotou como metodologia a semana composta. Para compor as seis semanas da amostra, foram selecionados aleatoriamente seis segundas-feiras, seis terças-feiras, etc. Como não há telejornal no domingo, foram feitos 36 sorteios para constituir o corpus. Pelo número elevado de sorteios, aumenta-se a chance de a amostra ser representativa, isto é, de ela nos revelar as características gerais da cobertura de crime na cidade no ano de 2004.

$\mathrm{Na}$ classificação, só consideramos os crimes contra a propriedade ou a pessoa. Embora sejam infrações, não foram contabilizados crimes de colarinho branco, ilegalidades no trânsito ou casos de corrupção de funcionários do Estado ou políticos que não tivessem vínculo direto com a polícia, o judiciário e a prisão. O total de notícias de crime foi de 82, o que corresponde a mais de duas notícias sobre crime por dia; de fato, o número mais freqüente de reportagens é de duas por dia. Em 30 dos 36 dias (83\%), havia pelo menos uma matéria na "escalada", isto é, na fala do apresentador antes de começar o telejornal, que equivaleria à primeira página de um jornal. De fato, $59 \%$ das notícias apareceram na "escalada", revelando assim a importância das notícias de crime no cotidiano da cidade.

Uma primeira distinção foi entre reportagens sobre eventos e reportagens genéricas, que tratam de novas estratégias para lidar com o crime, da necessidade de mais policiamento, dos números da criminalidade, etc. Como era de se esperar para a televisão, a cobertura focou os eventos: apenas quatro notícias (5\%) eram genéricas. A tabela abaixo dá a distribuição dos eventos noticiados $(\mathrm{N}=78)$ : 


\begin{tabular}{|l|r|}
\hline Eventos & Percentagem \\
\hline Campanhas da sociedade civil pela paz e segurança & $5 \%$ \\
\hline Evento no sistema judiciário & $1 \%$ \\
\hline Evento do sistema penitenciário & $10 \%$ \\
\hline Ação Policial & $26 \%$ \\
\hline Crime cometido por policial & $10 \%$ \\
\hline Ato violento-criminoso & $48 \%$ \\
\hline
\end{tabular}

O que chama imediatamente a atenção é a concentração das notícias (84\%) nos crimes cometidos por civis ou policiais e nas ações policiais (captura de criminosos, apreensão de objetos, incursão a favelas, etc.). O noticiário é basicamente focado no ato criminoso e no seu patrulhamento e prevenção. Tendo em vista o objetivo do artigo, limitaremos a análise aos crimes entre particulares e, na seqüência, analisaremos a imagem dos aparatos estatais de segurança em todas as notícias de crime. As tabelas abaixo condensam as informações sobre tipos de ato criminoso, local de ocorrência e relação entre vítima e agressor.

\begin{tabular}{|l|c|c|}
\hline Tipo de ato criminoso & $\mathrm{N}$ & $\%$ \\
\hline Roubo & 2 & $5 \%$ \\
\hline Agressão & 6 & $16 \%$ \\
\hline Homicídios & 4 & $11 \%$ \\
\hline Assaltos & 4 & $11 \%$ \\
\hline Tiroteios entre traficantes ou entre bandidos & 3 & $8 \%$ \\
\hline Crimes aleatórios (bala perdida, seqüestro-relâmpago, arrastão) & 10 & $27 \%$ \\
\hline Demonstração de força dos traficantes & 8 & $22 \%$ \\
\hline Total & 37 & 100 \\
\hline
\end{tabular}

\begin{tabular}{|l|c|c|}
\hline Local de concentração do ato criminoso & $\mathrm{N}$ & $\%$ \\
\hline Residência & 7 & $22 \%$ \\
\hline Casa noturna & 4 & $13 \%$ \\
\hline Praia & 1 & $3 \%$ \\
\hline Universidade & 1 & $3 \%$ \\
\hline Comércio, banco e carro-forte & 2 & $6 \%$ \\
\hline Rua & 17 & $53 \%$ \\
\hline Total & 32 & 100 \\
\hline
\end{tabular}

\begin{tabular}{|l|c|c|}
\hline Relação entre agressor e vítima & $\mathrm{N}$ & $\%$ \\
\hline Conhecido, com relação de familiaridade & 0 & 0 \\
\hline Conhecido, sem relação de familiaridade & 3 & $9 \%$ \\
\hline Desconhecido, mas por razões afetivas & 5 & $16 \%$ \\
\hline Desconhecido, mas sem relações afetivas & 24 & $75 \%$ \\
\hline Total & 32 & 100 \\
\hline
\end{tabular}

Em relação à primeira tabela, que diferencia o tipo de crime noticiado, a ordenação combinou dois critérios: a magnitude do dano corporal, real ou virtual, e a 
probabilidade de terem sido cometidos por estranhos. A suposição é a de que quanto maior a magnitude do dano e quanto mais eles forem cometidos por estranhos, mais assustadores eles são. Os aqui denominados "crimes aleatórios" são aqueles que já entraram no imaginário dos habitantes da cidade do Rio de Janeiro como sendo muito perigosos, difíceis de evitar e nos afetando durante nossa rotina diária. Quanto ao poder dos traficantes, são os atos criminosos que mostram que a lei na cidade - ou ao menos no entorno das favelas - é dada pelo crime organizado e que eles cada vez mais estendem sua zona de influência na cidade ou no que deveriam ser seus habitantes dignos (classificamos assim notícias que denunciavam a relação de traficantes com pagodeiros). Desse modo, se somarmos assaltos, tiroteios, crimes aleatórios e demonstração de força dos traficantes, veremos que $68 \%$ dos crimes que apareceram no telejornal já eram crimes com danos corporais (reais ou virtuais) de grande magnitude, com seleção aleatória de vítimas (assaltos e crimes aleatórios) e com a face do criminoso sendo o estranho, seja ele o bandido comum, seja ele a face mais assustadora do crime organizado. Cabe notar que apenas os homicídios, os crimes de lesões corporais e os roubos podiam ter sido cometidos por pessoas próximas à vítima, por um indivíduo semelhante a qualquer telespectador.

Para tornar mais sensível essa preferência editorial pela vitimização aleatória, pesquisamos em todas as 82 notícias se elas mencionavam ou não os termos "bala perdida" ou "vítima de tiroteio". O resultado surpreendente é que 21 notícias (ou 26\%) mencionavam esses termos. A chance, portanto, de algum dia um telespectador ligar o telejornal e ouvir alguma menção de bala perdida é de uma em quatro.

De todo modo, estamos superestimando o número de crimes que poderia ter sido cometido por um indivíduo semelhante ao telespectador. Na tabela seguinte, sobre o local de concentração dos atos criminosos, há mais um elemento a mostrar como o critério de seleção dos editores do telejornal é o crime cometido por estranhos com seleção aleatória de vítimas e que ocorrem na rotina de qualquer indivíduo, isto é, os crimes que propõem a identificação do espectador com a vítima. Cabe dizer que só aparecem 32 crimes aqui (e não 37, que foi o total de atos criminosos no período) porque algumas demonstrações de força do tráfico não têm localização na medida em 
que atingem a sociedade inteira, como é o caso de denúncia de aliança com cantores. O local de concentração foi ordenado segundo dois princípios: o primeiro é a separação entre público e privado e o segundo é a divisão entre o escolhido e o rotineiro. Ir à boate ou a bares pode ser visto como uma escolha (e, portanto, o crime pode ser evitado pela decisão de não sair); por outro lado, ir a certos locais ou é um hábito de grande parte da população (a praia) ou uma necessidade - bancos, lojas, universidade, passar por ruas a pé, de ônibus ou de carro. O total de crimes que ocorreram na rua, praia, universidade ou comércio é de $65 \%$.

Os espaços públicos e semi-públicos da cidade são constituídos como lugares perigosos. Como argumentou o pai de uma vítima de bala perdida durante um assalto a banco noticiado no dia cinco de novembro, também em casa se correm riscos. Dos sete casos onde o local de concentração era a residência, três foram assaltos, um foi a “ordem de despejo" de uma moradora de favela promulgada por traficantes e o outro foi uma chacina que a polícia afirmou ser de responsabilidade do tráfico.

A última tabela analisou a relação entre agressor e vítima nos crimes noticiados. O primeiro nível - "agressor conhecido, mas com relação de proximidade" - compreende namorados, amantes, cônjuges, parentes ou amigos da vítima. O item "conhecido, mas sem relação de familiaridade" designa um agressor que conhecia casualmente a vítima, sem ter estabelecido alguma relação afetiva, como colega de trabalho ou vizinho. O terceiro item classificava o agressor desconhecido, mas que agredia a vítima por razões passionais; os casos típicos são brigas em bares ou no trânsito. Por fim, o último item é o agressor desconhecido, sem relação alguma com a vítima. Como se vê na tabela, para quem pensa o que existe a partir do que a mídia noticia, não existem crimes passionais no Rio de Janeiro; não houve nenhum caso onde o agressor era conhecido e tinha relação de familiaridade. Inversamente, $75 \%$ dos crimes teriam sido cometidos por estranhos, sem relação alguma, isto é, crimes com seleção aleatória de vítimas.

Detalhando um pouco mais, deve-se dizer que, nas três notícias onde o agressor era conhecido (de fato, dois casos), o agressor ou era um sócio do extraficante Escadinha ou era um caseiro - morador de uma favela, como as reportagens insistiam - que ajudou no latrocínio de um casal de norte-americanos. 
Nos dois casos, não há nenhuma proposição de identificação da audiência com o agressor. Quanto aos crimes cometidos por estranhos, mas com razões passionais, com exceção de um, todos foram cometidos por “pitboys”, isto é, por indivíduos já estigmatizados, colocados à distância da audiência. Assim, em apenas uma notícia das 37, os agressores podiam ser vistos como semelhantes à audiência: trata-se da agressão a um policial por um médico, sua mulher e filha ao receberem uma multa de trânsito. Uma forma de corroborar esse privilégio dos crimes cometidos por estranhos é o fato de 41 reportagens (50\% do total) mencionarem os termos "tráfico", "traficantes" ou sinônimos, como "facção criminosa".

Para apreender o modo como o telejornal construía a idéia de sofrimento evitável, analisamos, para toda e qualquer notícia, independentemente de seu foco principal, se havia alguma denúncia à ação do Estado nas suas três funções principais para a segurança: polícia, prisão e judiciário. Do total de 82 matérias, 52 (63\%) continham algum tipo de crítica; em termos de freqüência diária, em apenas três dos 36 não houve nenhuma reportagem com alguma denúncia sobre falhas na atuação dos aparatos estatais de segurança.

O total de críticas foi de 75; este total é maior do que o número de notícias, pois é comum haver mais de um tipo de crítica numa mesma matéria. Em relação à atuação do judiciário, em quatro notícias sua atuação foi denunciada, seja porque concedia hábeas corpus a suspeitos, seja porque juízes se diziam contrários à proposta policial de haver uma lista em boates impedindo a entrada de "baderneiros". Em relação à prisão, houve nove críticas em oito notícias. Essas denúncias ou propunham que motins, rebeliões e fugas são constantes (5), ou que os agentes penitenciários são corrompidos pelos presos (3) ou, no caso mais grave, que os bandidos continuam a cometer crimes de dentro da prisão ao ordenarem assassinatos a seus comparsas (1).

Se o foco do noticiário é o ato criminoso e a ação policial, é claro que haveria muito mais críticas à polícia; houve 62. Um primeiro tipo de crítica diz respeito ao trabalho de inteligência e apuração de crimes, num total de oito. Ou bem a polícia não soluciona os crimes, ou não vigia corretamente, ou bem chega tarde demais quando requisitada ou, se chega a tempo, os bandidos ainda assim fogem. 
O segundo tipo de crítica diz respeito às falhas no patrulhamento - houve um total de 34. Uma primeira denúncia pede maior policiamento ou reclama que o reforço de contingente só acontece após a ocorrência de um crime; 13 notícias traziam esse tipo de crítica.

Uma segunda falha no patrulhamento é aquela onde se denuncia que a proximidade da polícia não adianta, seja porque os crimes ocorrem perto da polícia e ela não consegue impedir a ação de bandidos, que não se intimidam com sua presença, seja porque os moradores preferem obedecer aos bandidos, pois temem mais a estes do que são tranqüilizados pela presença ostensiva da polícia. Houve esse tipo de crítica sobre a ineficácia da proximidade da polícia em sete notícias.

Uma terceira crítica sobre o patrulhamento policial propõe que a proximidade da polícia é perigosa, na medida em que são muito freqüentes os tiroteios entre policiais e bandidos e, assim, os cidadãos inocentes (aí não incluídos os moradores de favelas) podem se tornar vítimas: sete notícias continham essa crítica. O caso mais curioso, que certamente confundiria estrangeiros, foi uma reportagem de 21 de fevereiro de 2004 que reportava a medida anunciada pelo chefe de polícia para aumentar a segurança dos motoristas na linha amarela após a morte por bala perdida de uma mulher que passava de carro: a polícia resolveu se afastar da proximidade da via expressa. Aumentar a segurança dos motoristas é fazer com que a polícia “desapareça”.

O último tipo de crítica do patrulhamento policial insinua que a polícia, ao invés de intimidar, está intimidada pelos bandidos. Essa crítica apareceu em três notícias; uma reportagem de 13 de julho de 2004 mostra que, após a morte de um gerente de banco durante um assalto de carro, a delegacia policial próxima ao local do crime teve sua entrada fechada com correntes; o delegado justificou essa medida de proteção aos policiais com o argumento de que a delegacia ficava perto de 14 favelas.

Em 55 (71\%) das 75 críticas à atuação do Estado em relação à segurança, estamos diante da construção do sofrimento evitável tal como proposto pelo populismo conservador, isto é, se as leis fossem mais rigorosas, se a prisão contivesse os riscos postos pelos criminosos e se houvesse mais polícia, de modo a intimidar os 
bandidos, não haveria tantos crimes na cidade do Rio de Janeiro. Mas parte significativa das que restam (14 notícias) representam um caso intermediário, que seriam os excessos durante ações policiais nas favelas. Parte da audiência pode pensar que se trata de abuso dos direitos humanos dos moradores de favela; contudo, outros pensarão que esses excessos significam danos colaterais inevitáveis na "guerra" contra o tráfico. O caso típico é o de moradores de favela inocentes mortos por balas perdidas durante incursão policial; a reportagem não deixa claro se houve ou não negligência criminosa da parte da polícia. No mais das vezes, o que se diz é que a polícia reagiu ao ser atacada.

Em seis notícias - menos de 10\% do total de críticas - houve denúncia efetiva do telejornal sobre má conduta policial. Em quatro reportagens, houve a denúncia de negligência criminosa e em duas reportagens de um mesmo caso policiais são acusados de fabricar evidências para incriminar um inocente. Em termos de freqüência, cabe notar que em apenas quatro dos 33 dias em que houve denúncia de atuação dos aparatos estatais de prevenção, julgamento e punição, o tom da crítica era a má conduta policial, especialmente porque se associava a negligência criminosa na favela com algum caso de crime de extorsão ou abuso de autoridade. Desse modo, ao longo de 2004, havia uma probabilidade de cerca de 80\% de um indivíduo assistir ao RJ-TV e se deparar com alguma reportagem que aliava a ineficiência do Estado ao poder dos criminosos.

O último elemento na descrição da composição midiática da segurança pública analisa a distribuição do direito à fala nas reportagens sobre crime. Em 46 notícias, apenas o apresentador ou repórter falaram. Os policiais e seus representantes falaram em 29 notícias, ou 35\% do total. Se separarmos aquelas onde apenas a voz da emissora e a voz da polícia estiveram presentes, temos 57 reportagens (70\% do total). Especialistas - juízes, sociólogos, criminologistas, representantes do Estado - apareceram em seis notícias e representantes da sociedade civil organizada em cinco; houve superposição em duas reportagens, significando que em apenas nove reportagens (11\%) houve uma voz externa àqueles que estão diretamente envolvidos na notícia de um evento criminoso: o repórter, a vítima e a polícia. 
Em 12 notícias aparece a voz da vítima direta ou de seus parentes e amigos. Refinando a análise, essa fala pode ou denunciar a violência do suspeito (3), ou contestar a versão policial do incidente (5), como nas ações policiais onde teria havido negligência criminosa, ou afirmar que o ocorrido prova que a cidade é perigosa (4). Talvez a fala mais interessante seja a da vítima virtual, aquela cuja relação com o incidente se limita a de morar próxima ou ter de passar perto do local de ocorrência e que, portanto, se percebe em risco. Essa voz, que representa a audiência atemorizada pela notícia, está presente em 12 reportagens. Sua função precípua é atestar que um crime semelhante pode ocorrer novamente, atingindo qualquer um da audiência. Se somarmos a voz da vítima virtual à voz das vítimas diretas que denunciam o perigo da cidade, temos 16 notícias (20\%) propondo diretamente que a audiência está em risco.

Há também ocasiões onde a vítima virtual é convocada para discutir as políticas públicas de segurança. No dia 12 de agosto, uma reportagem anuncia a nova destinação da Casa de Custódia de Benfica, que, dois meses antes, teve uma rebelião com vários mortos provocada pelo conflito entre facções. Ao invés de abrigar detentos à espera do julgamento, passaria a ser um centro de triagem para os prisioneiros aguardando a liberação, que receberiam assistência especializada de psicólogos e servidores sociais. A notícia não abre espaço nem para o governo, nem para especialistas. A única voz é a de uma moradora não-identificada do bairro. Logo no início reclama que os agentes deixam os presos ficarem gritando de madrugada, perturbando o sono daqueles que pagam seus impostos. Após ter dito que vive em desespero constante desde a rebelião, julga o sentido da proposta governamental: a medida não vai funcionar, pois "vão misturar outra vez facções diferentes, num bairro que tem várias favelas; vai ser muito pior”. A reiteração do senso comum sobre a criminalidade do Rio de Janeiro - os traficantes, as favelas - tem o peso de verdade pela experiência de sofrimento.

\section{4- Conclusão}

Um dos elementos fundamentais de um processo decisório como o do voto em uma campanha eleitoral é estabelecer um diagnóstico da realidade a partir do qual se propõe cenários resultantes da escolha de uma opção. Em um referendo com 
escolha binária, era de se esperar que um lado defendesse a continuidade argumentando que a decisão contrária pioraria o estado de coisas, enquanto o outro construiria cenários positivos decorrentes de uma eventual mudança. Quando o diagnóstico sobre o estado de coisas é dominantemente negativo - o que é o caso da segurança pública - a opção pela mudança parecia ser "natural" e foi com base nesta disposição incial que o eleitorado vinha se manifestando favoravelmente à proibição nos meses que antecederam o referendo. A esta dimensão, costumeiramente tida como 'racional', vem somar-se (ou contrapor-se) outras, de caráter afetivo e simbólico: quem apóia ou legitima certas posições e avalições, quem confere credibilidade aos diagnósticos e prognósticos difundidos na campanha. Por fim, como já antecipado, as campanhas terão que definir seus campos de pertencimento, convidando a audiência a fazer parte de um "nós".

A percepção construída pela mídia sobre a segurança pública, se não foi determinante para o resultado, constituiu o ambiente semântico onde os discursos de campanha adquiriam o seu sentido. Um primeiro aspecto a ser destacado é a ausência quase total dos crimes de proximidade na mídia. A outra face dessa ausência - e que a reforça ainda mais - é o privilégio dos crimes com seleção aleatória de vítimas ocorridos em lugares ou que fazem parte da rotina de muitos, ou onde deveríam estar protegidos. Crimes aleatórios cometidos por estranhos cuja face não tem qualquer semelhança ou afinidade com os indivíduos comuns: o criminoso é um "bandido". Desse modo, a audiência é sistematicamente endereçada como vítima virtual; jamais como um criminoso em potencial, como poderia ser o caso nos crimes de proximidade, dependendo de sua narrativa.

Na conformação do ambiente semântico onde os discursos serão acolhidos, a cobertura televisiva atua primeiramente restringindo o lugar a partir do qual faria sentido tomar uma decisão. Se os indivíduos querem fazer alguma coisa contra a "violência", a decisão deve afetar a segurança pública. E mesmo que a proibição do comércio de armas reduza o número de mortes acidentais ou os crimes de proximidade (como insistiu a campanha do SIM no início do horário eleitoral), essa redução em nada altera o medo do crime. Se aqueles que querem mudar não utilizam a segurança pública como lugar de construção de cenários, os defensores da 
continuidade estão livres para prognosticar a piora do estado de coisas decorrente da decisão: restringir o comércio significaria o fim da possibilidade de um cidadão se defender e daria a certeza aos "bandidos" sobre a vulnerabilidade das vítimas. Ao mesmo tempo, frisar que muitas mortes se devem a crimes de proximidade contrariava a "realidade" tal como ela se dava a ver nos meios de comunicação e, sobretudo, colocava a audiência na posição de um criminoso em potencial, enquanto ela se pensa a partir da inocência da vítima. O "nós" de uma campanha que frisa os crimes de proximidade em um "mundo" em que esses crimes ou não parecem existir, ou tem pouco relevância, repugna o espectador, pois o aproxima do "eles".

Outro aspecto importante da cobertura midiática de crimes na recepção da propaganda é a preferência pela voz do indivíduo qualquer e o privilégio concedido à autoridade da experiência - como vítima ou policial - em detrimento do saber científico ou de dados quantitativos. O que vale - e aparecer na mídia atesta este valor - é o que qualquer um sabe pelo que viveu ou foi informado. De um lado, o que todo mundo sabe e a experiência dos que lidam diariamente com crime podiam ser usados para desqualificar dados estatísticos sobre a prevalência de crimes de proximidade; de outro lado, o privilégio do indivíduo qualquer neutralizava o uso de artistas, ainda mais em face do argumento de que, por serem ricos, eles não partilham a experiência de insegurança com o indivíduo qualquer.

Talvez o aspecto decisivo tenha sido o modo como o telejornal construiu a idéia de sofrimento evitável. Como vimos, na sua grande maioria, os crimes difundidos na mídia poderiam ter sido "evitados" se os aparatos estatais responsáveis pela segurança pública não fossem incompetentes ou corrompidos. A narrativa midiática propõe uma separação entre o "nós", constituído pelos indivíduos comuns assustados com a "violência urbana", e o "eles", que compreende os bandidos e o Estado incapaz de prover segurança a seus contribuintes-clientes. Essa característica da cobertura de crimes favoreceu os defensores do comércio de armas, cuja propaganda procurou confundir o eleitorado a respeito da origem da iniciativa do referendo, que por seu ineditismo e extemporaneidade já lhe parecia obscura. A iniciativa foi dominantemente atribuída ao governo, especialmente o federal, então assolado por escândalos de corrupção. Prevaleceu a interpretação de que, como o 
governo nada faz para a segurança das vítimas virtuais, propôs um referendo para dar a impressão que faz alguma coisa; pior, a manobra diversionista dos "políticos", além de retirar o “direito' do cidadão de se defender dos "bandidos”, daria a estes a certeza da vulnerabilidade de suas vítimas.

Em suma, a mudança intensa e rápida da opinião pública em relação ao comércio de armas deveu-se ao fato de que a campanha do NÃO soube explorar a percepção de segurança pública construída ao longo dos últimos anos pela mídia. $\mathrm{O}$ SIM, por outro lado, foi incapaz de demonstrar que representava uma possibilidade efetiva de mudança, uma vez que a realidade que ele pretendia mudar não correspondia ao cenário de insegurança construído a partir das percepções difundidas pela mídia. À sensação de insegurança somou-se a incerteza do voto e, do ponto de vista racional, os eleitores votaram a favor dos riscos bem conhecidos do presente em detrimento dos riscos desconhecidos do futuro.

A campanha do referendo na TV foi, desse ponto de vista, uma disputa entre as "vítimas reais" (sempre, atuais e particulares), que o SIM pretendeu colocar em cena ao seu lado, e as "vítimas virtuais" (vítimas futuras e universais) que o NÃO se propunha a defender. No confronto, as primeiras foram derrotadas. A campanha do SIM exigia dos eleitores que eles renunciassem à sua condição universal de vítimas e aceitassem se tornar co-responsáveis - não apenas no momento do voto, mas no seu cotidiano - pela segurança e pela insegurança públicas. Esta era uma renúncia que o eleitor não estava nem preparado, nem disposto a fazer. Foi a ela, sobretudo, que os eleitores disseram NÃO, muito antes do que à defesa de um "direito" que, em sua maioria, nunca haviam se preocupado em exercer.

\section{5 - Bibliografia}

Comaroff, J. C., J. L. 2006. Figuring Crime: quantifacts and the production of the un/real. Public Culture 18.

Cunha, C. V. 2006. "Referendo das armas": a propaganda televisiva e percepções da população. Comunicações do Iser, 25, 62, p. 74-92.

Garland, D. 2001. The culture of control: crime and social order in contemporary society. Chicago: University of Chicago Press 
Lissovsky, M. 2006. A campanha na tevê e a desventura do SIM que era Não. Comunicações do Iser, 25, 62, p. 40-63.

Luhmann, N. 1993. Risk: a sociological theory. New York: A. de Gruyter.

Simon, J. 2007. Governing through crime: how the war on crime transformed American Democracy and created a culture of fear. Oxford: Oxford University Press.

Vaz, P.; Sá-Carvalho, C.; Pombo, M. 2006. A vítima virtual e sua alteridade: a imagem do criminoso no noticiário de crime. Revista FAMECOS, v. 30, p. 71-80.

Vaz, P.; Sá-Carvalho, C.; Pombo, M. 2005. Risco e sofrimento evitável: a imagem da polícia no noticiário de crimes. E-Compós, v. 4, p. 1-22. 